\title{
Species composition and fire: non-additive mixture effects on ground fuel flammability
}

\section{Cassandra van Altena ${ }^{\dagger}$, Richard S. P. van Logtestijn, William K. Cornwell and Johannes H. C. Cornelissen*}

Systems Ecology, Department of Ecological Science, Faculty of Earth and Life Sciences, VU University, Amsterdam, Netherlands

\section{Edited by:}

Francisco I. Pugnaire, Consejo

Superior de Investigaciones

Científicas, Spain

Reviewed by:

Martín R. Aguiar, University of

Buenos Aires, Argentina

Wade C. Tozer, Macquarie University,

Australia

*Correspondence:

Johannes H. C. Cornelissen, Systems

Ecology, Department of Ecological

Science, VU University Amsterdam,

De Boelelaan 1085, 1081 HV

Amsterdam, Netherlands.

e-mail: j.h.c.cornelissen@vu.nl

\section{${ }^{+}$Present address:}

Cassandra van Altena, Biometris, Wageningen University, P.O. Box 47, 6700 AC Wageningen, Netherlands.
Diversity effects on many aspects of ecosystem function have been well documented. However, fire is an exception: fire experiments have mainly included single species, bulk litter, or vegetation, and, as such, the role of diversity as a determinant of flammability, a crucial aspect of ecosystem function, is poorly understood. This study is the first to experimentally test whether flammability characteristics of two-species mixtures are nonadditive, i.e., differ from expected flammability based on the component species in monospecific fuel. In standardized fire experiments on ground fuels, including monospecific fuels and mixtures of five contrasting subarctic plant fuel types in a controlled laboratory environment, we measured flame speed, flame duration, and maximum temperature. Broadly half of the mixture combinations showed non-additive effects for these flammability indicators; these were mainly enhanced dominance effects for temporal dynamics - fire speed and duration. Fuel types with the more flammable value for a characteristic determined the rate of fire speed and duration of the whole mixture; in contrast, maximum temperature of the fire was determined by the biomass-weighted mean of the mixture. These results suggest that ecological invasions by highly flammable species may have effects on ground-fire dynamics well out of proportion to their biomass.

Keywords: biodiversity, carbon cycling, fuel type, non-additivity, physical configuration, species interaction, trait

\section{INTRODUCTION}

Since the origin of plants on Earth, fire has played major direct and indirect roles in the carbon cycle and climate (Conard and Ivanova, 1997; Jin and Roy, 2005; Flannigan et al., 2009; O'Donnell et al., 2009) as well as in the formation of communities and the functioning of ecosystems (Reich et al., 2001a; Schwilk and Ackerly, 2001; Woodward et al., 2004; Pausas and Keeley, 2009). Fire can structure communities through its filtering role, selecting those plant species that can survive a fire or regenerate after one (Pausas and Verdu, 2008). For example, it has been hypothesized that fire may have played an important role in the spread of C4 plants (Bond et al., 2005).

The properties of the vegetation of a community determine, together with climatic conditions and ignition sources, the frequency and propagation of wildfires. Interspecific variation in plant traits is known for its predictive capacity of ecosystem carbon and nutrient dynamics (Lavorel and Garnier, 2002) and fire frequency (Schwilk and Caprio, 2011), and the trait-based approach to quantifying the functional variation in vegetation is becoming popular (Westoby et al., 2002; McGill et al., 2006). The most important properties of plants related to flammability are structure, moisture content, and chemistry of living and dead parts (van Wilgen et al., 1990; Bond and Van Wilgen, 1996; Dimitrakopoulos, 2001; Behm et al., 2004; Curt et al., 2011; Ganteaume et al., 2011; Schwilk and Caprio, 2011), with fire spread driven in different circumstances by characteristics of the living plant and/or characteristics of the litter bed. Important traits of plants reported to influence their flammability are high surface-to-volume ratio, fuel moisture retention capacity (or desiccation rate), and particle size (Auclair, 1983; Bond and Van Wilgen, 1996; Cornelissen et al., 2003; Scarff and Westoby, 2006; Plucinski and Anderson, 2008; Schwilk and Caprio, 2011).

In addition to the effects of plant traits on fire properties, the composition of species in mixed stands of vegetation, and their joint physical configuration, are also relevant. The effects of species composition on many aspects of ecosystem function have received intense interest (Hooper et al., 2005), but these studies have not previously considered the cumulative effect of vegetation properties on aspects of ecosystem flammability. There are equally likely to be effects of species interactions on ecosystem flammability, i.e., effects that differ from the expected average effects of the component species. Understanding the fire behavior of species mixtures, especially the potential for non-additivity, would greatly help to improve predictions when scaling up from effects of traits of individual species to effects of whole plant communities on fire regimes; after all, the vegetation rarely consists of a single species. Non-additive species mixture effects have been shown for productivity (Hector, 1998; Dukes, 2001; Reich et al., 2001b), nutrient retention (Hooper and Vitousek, 1998), water economy (Michel et al., 2012), and in some cases for litter decomposition (Wardle et al., 1997; Hättenschwiler et al., 2005; Quested et al., 2005; Perez-Harguindeguy et al., 2008; Lecerf et al., 2011). However, while much research on the flammability of plant materials has been conducted on single species (Gill and Moore, 1996; Scarff and Westoby, 2006; Alessio et al., 2008; Plucinski and Anderson, 2008) and some on bulk mixtures of plants (Catchpole et al., 1993; 
Volokitina and Sofronov, 2002; Plucinski, 2003; Ormeno et al., 2009), non-additive effects of plant mixtures on flammability, have, to our knowledge, never been explicitly investigated.

In this research, we focus on the flammability of ground layer vegetation and litter, represented here by monospecific fuels and two-species mixtures of five contrasting subarctic plant materials (fuel types) of four locally abundant species. To define flammability itself we follow Anderson (1970), who described it in terms of ignitability, sustainability, and combustibility; in our experimental approach, ignitability, and sustainability are characterized by flame speed and time to flame extinction (see Rothermel, 1972) and combustibility by maximum temperature. We hypothesize that the species in the mixture with the highest flame speed, the longest time to flame extinction or the highest maximum temperature will determine the value of this flammability characteristic of the whole mixture most strongly. In other words, we expect to see non-additive effects in the sense that one species dominates the other with respect to flammability ("enhanced dominance"). We also hypothesize that mixtures containing the fuel type with the most extreme values measured for a fire characteristic are most likely to show non-additive effects. To test these hypotheses, we conducted an experiment with standardized burns with both monospecific and mixed fuels in a controlled laboratory environment.

\section{MATERIALS AND METHODS STUDY SITE AND SPECIES}

We collected plant material near Abisko Scientific Research Station in northern Sweden $\left(68^{\circ} 21^{\prime} \mathrm{N}, 18^{\circ} 49^{\prime} \mathrm{E}\right)$ in September 2009. Fire frequency in this area is not known, but a similar shrub tundra site in Alaska has been estimated to have a historical fire frequency of 144 years (Higuera et al., 2008). Increases in fire frequency due to changes in climate, e.g., more frequent dry late summers, have already been reported for the boreal forests in Northern America (ACIA, 2005) and are expected for northern tundra as well. The largest tundra ground-fire reported in 2007 in Alaska, the Anaktuvuk River Fire, indeed took place in an exceptionally dry summer (Jones et al., 2009). Ground fires in the tundra, and other biomes, are very important ecologically (Bond et al., 2005) and have a large effect on climate (Rocha and Shaver, 2011).

We chose five contrasting fuel types of three plant and one lichen species that are abundant near the ground in the subarctic, as well as in boreal forest and heathland: branches and leaves from the small deciduous tree/shrub Betula pubescens ssp. czerepanovii Ehrh.; twigs (including leaves) of the evergreen dwarf shrub Empetrum nigrum (L.) ssp. hermaphroditum Hagerup; the pleurocarpous moss Hylocomium splendens (Hedw.) B.S.G. and the foliose, $\mathrm{N}_{2}$-fixing lichen Nephroma arcticum (L.) Torss. Hereafter these species are referred to by their genus name for brevity. For each fuel type we collected bulk samples from $>20$ (Betula) to $>100$ individuals (other species) from several sites. We collected dead but undecomposed Betula branches of 5-8 $\mathrm{mm}$ diameter from the ground, while very recently senesced leaves were removed from the tree by gently jostling the branches. The upper $10-30 \mathrm{~cm}$ shoot sections of Empetrum were cut from the plant, Hylocomium and Nephroma were easily collected as patches from the litter horizon and rocks in open Betula woodland respectively. We air-dried all materials and then stored them in open boxes in a laboratory until further preparation.

We removed all debris from plant materials by hand. To obtain homogeneous mixtures of two fuel types, Betula branches, Empetrum, Hylocomium, and Nephroma were cut to $4-10 \mathrm{~cm}$ long fragments, retaining structure of either single or branched shoots. This allowed fuel types to both fit into the experimental burns and to be mixed to homogeneity with other fuel types.

\section{TRAIT MEASUREMENTS}

We chose five traits as representative of structure, moisture properties, and chemistry of the fuels ( $c f$. Plucinski and Anderson, 2008): surface area per volume (area per particle volume), fuel density (gram dry mass per particle volume), packing ratio (particle volume per fuel bed volume), dry matter content (particle dry mass per saturated mass), and fuel C:N ratio. We acknowledge that the different species vary greatly also in (secondary) chemical composition, but it was beyond the scope of this study to quantify this comprehensively. Fresh surface areas of leaves, branches, Hylocomium shoots, and Nephroma thalli were determined with a LI-3100 Area Meter (LI-COR Inc., Lincoln, Nebraska USA), where the measured projected area of leaves, moss, or lichen was multiplied by $t$ to give total area; area of Betula branches was calculated as scanned area $\times \pi$. For Empetrum, areas of leaves and branches of representative subsamples were determined separately by measuring diameter and length under a dissecting microscope. The average number of leaves per gram branch was counted, so that the surface area of a foliated Empetrum shoot could be calculated. These measurements were also used to calculate the volume of Empetrum. The fresh volumes of Betula leaves, Hylocomium and Nephroma were measured by putting small pieces of each material in a pycnometer, following Vernescu and Ryser (2009). Both fresh volume and area were divided by dry mass to determine fuel density and area per volume respectively. We measured dry mass after oven-drying at $70^{\circ} \mathrm{C}$ for at least $60 \mathrm{~h}$. For the packing ratio, defined as the volume of fuel divided by the volume of total space, we placed fuel types in their natural or spontaneously assumed configuration (see below) in a container of known volume; subsequently we determined the dry mass of this subsample (see above). Total particle volume of this subsample was determined by conversion from fuel density (see above). C:N ratio was measured after pre-drying, grinding, and final drying (at $70^{\circ} \mathrm{C}$ for at least $24 \mathrm{~h}$ ) of five samples for each fuel type (two for Empetrum), followed by dry combustion for $\mathrm{C}$ and $\mathrm{N}$ concentrations in a Flash EA1112 elemental analyzer (Thermo Scientific, Rodano, Italy).

\section{FIRE EXPERIMENT}

To screen for flammability, we developed a standardized laboratory assay based largely on the methodology of Plucinski and Anderson (2008). The plant material was burned inside a fire-proof ring of steel mesh ( $25 \mathrm{~cm}$ diameter, $3 \mathrm{~cm}$ depth) on a solid base, such that air only can enter the fire from the sides or the top. We performed burns with three different types of ring content: either (1) filled entirely with a monospecific fuel type, (2) with mixtures, or (3) with a monospecific fuel type in one semicircle, which controls for the single species volume in the mixture trials while holding fuel depth constant. 
All 10 possible combinations of mixtures with two fuel types were included, with the volume of each material equal to half of the volume used in the monospecific burns, resulting in 50:50 fuel mixtures. Volume controls were burned to test whether potential non-additive effects might simply be caused by the fact that in the mixtures for each fuel type only half of the amount used in the monospecific rings was burned. In the most extreme hypothetical case, the "other" species in the mixture would be infinitely low in density, so that any apparent mixture effect could be explained by only half the mass of the target species being included in the observed mixture, compared to the mass in the full monospecific ring used for deriving expected flammability values. Thus, if substantial differences in fire characteristics were measured between full and volume control rings for a given fuel type, it would mean that any non-additive mixture effects might be explained largely by the absolute amount of material of the high caloric fuel type in monospecific versus mixed fuel.

Six replicates were conducted for monospecific and mixture burns and at least three replicates for the trials with half-full rings. The material was placed loosely (broadly mimicking spontaneous natural packing) and distributed equally over the ring (or half of the ring respectively) till it was full for the monospecific burns. For mixtures, the two fuel types were first mixed by hand in a container until the mixture was homogeneous and was placed in the ring. The same mass for the first replicate of one monospecific fuel or mixture was used for the other replicates (Table 1). One replicate of each of all treatments was sealed separately in a plastic bag on the same day (see below) so that all air-dried samples in the same statistical block (see below) would be in equilibrium with the same air humidity in the lab the burns. We assumed that fuel moisture content in the plastic bags would not change until the burn, which was on the day after sealing. The range of lab air humidity among sealing days (blocks) was approx. $28 \%$.

The fire experiment was carried out in the Fire Laboratory of Amsterdam for Research in Ecology (FLARE) located at VU University Amsterdam, The Netherlands. Prior to each series of burns, the fume hood was turned on and experiments started when room temperature was $18 \pm 2^{\circ} \mathrm{C}$. Ventilation was held at constant, moderate speed, and the air drawn in from outside by the extractor fan was first warmed to room temperature. The ring was positioned beneath the fume hood on a fire-resistant plate and material was ignited by lighting a cotton disk $(5.7 \mathrm{~cm}$ diameter, folded twice) injected with $1 \mathrm{ml}$ of $96 \%$ ethanol, placed in the center of the ring. Three flammability variables were measured during each burn flame speed $(\mathrm{cm} / \mathrm{min})$ was measured by clocking when the outer border of the ring was reached by the flame, as well as the time until the actual burning stopped (flame duration, seconds). Maximum temperature $\left({ }^{\circ} \mathrm{C}\right)$ was defined as the average of the maximum temperatures of five thermocouples ( $1 \mathrm{~mm}$ thick type $\mathrm{K}$ thermocouple, TC Direct, Uxbridge, UK) that were placed equally around the ring, with the tip of each thermocouple $12.5 \mathrm{~cm}$ from the center and approximately $1 \mathrm{~cm}$ above the surface of the fuel; temperature was recorded every second. The thermocouples could measure temperatures up to $1100^{\circ} \mathrm{C}$ and temperature data was analyzed with TC Meas, a program self-designed in Labview.

All of the fuel burned completely in most burns but in a few replicate mixtures containing Betula leaves, a small fraction of the leaves remained unburned at the bottom of the ring. In all burns the sample burned at the first ignition attempt, except for one replicate of Betula branches which ignited at the second attempt. Since this did not give different values compared to the other five replicates, it was included in all further analysis.

\section{DATA ANALYSIS}

For each of the monospecific and mixed species fuel types, one replicate was burned per day to obtain a randomized block design with day as a blocking factor. However, it turned out that there were no significant differences between days, so that eventually a one-way ANOVA (material as fixed factor) with a Tukey post hoc test was used to test for differences between the monospecific fuel types for each flammability variable (flame speed and flame duration were $\log _{10}$-transformed to better meet normality conditions). Relations between trait values and flammability variables were tested with both Pearson and Spearman rank correlations on averages calculated for each fuel type to detect linear or other monotonic relationships. Observed values of the mixture experiments for each flammability value were compared with expected values. These expected values were calculated as the average of the flammability variables measured in the monospecific burns of the component species for each day (resulting in six expected values). We calculated both volume-weighted (50:50) and massweighted averages to create two sets of expected values. For the mass-based expectation the expected value $=[$ mass fraction of fuel $\mathrm{A} *$ behavior of fuel $\mathrm{A}]+[$ mass fraction of fuel $\mathrm{B} *$ behavior

Table 1 | Different fuel types used together with codes, masses used for full and half-full rings and measured traits.

\begin{tabular}{|c|c|c|c|c|c|c|c|}
\hline Fuel type & Code & $\begin{array}{l}\text { Mass fuel } \\
\text { type }^{1}(\mathrm{~g})\end{array}$ & $\begin{array}{l}\text { Density } \\
\left(\mathrm{g} / \mathrm{cm}^{3}\right)\end{array}$ & $\begin{array}{l}\text { Specific area } \\
\left(\mathrm{cm}^{2} / \mathrm{g}\right)\end{array}$ & $\begin{array}{l}\text { Dry matter } \\
\text { content }(\mathrm{mg} / \mathrm{g})\end{array}$ & $\mathrm{C}: \mathrm{N}$ ratio & Packing ratio \\
\hline Betula pubescens branches & $\mathrm{BB}$ & $170[85]$ & $0.43(0.03)$ & $16.0(1.0)$ & $474(29.0)$ & $82.7(5.7)$ & $0.17(0.013)$ \\
\hline B. pubescens leaves & $\mathrm{BL}$ & 35 [17.5] & $0.29(0.02)$ & $347(16.8)$ & $316(9.8)$ & $50.5(3.7)$ & $0.05(0.003)$ \\
\hline Empetrum nigrum shoots & $E$ & $41[20.5]$ & $0.31(0.06)$ & $115(23.6)$ & $625(34.4)$ & $89.6(1.0)^{2}$ & $0.09(0.002)$ \\
\hline Hylocomium splendens (moss) & $\mathrm{H}$ & $14[7]$ & $0.15(0.06)$ & $384(32.4)$ & $326(8.5)$ & $70.4(5.5)$ & $0.15(0.08)$ \\
\hline Nephroma arcticum (lichen) & $\mathrm{N}$ & $50[25]$ & $0.33(0.03)$ & $145(14.2)$ & $342(11.1)$ & $21.1(1.4)$ & $0.09(0.006)$ \\
\hline
\end{tabular}

${ }^{1}$ Mass of monospecific full ring [mass of monospecific half-full ring].

${ }^{2} N=2$.

Trait values are averages $(N=5)$, with SEs included between parentheses. Masses used for half-full rings are also the masses used for mixtures. 
of fuel B]. The volume-based and mass-based expectations are two alternate benchmarks for additivity. Mass-based expectations for other ecosystem functions are discussed in detail by Garnier et al. (2004). Because the spatial spread of fire is crucial, the volume-based measures of fuel are also important, as they give equality in species contributions to fuel bed structure and their consequent effect on oxygen supply to support the fire; as such, we consider volume-based additivity a very relevant benchmark. For each flammability outcome, the results may be mass-additive, volume-additive, or deviate from both. Which of these three outcomes is most common is informative for understanding of the mechanisms that act when fire ignites and then travels through a mixed litter bed.

For the three flammability variables, a paired $t$-test was used to test for non-additive effects (deviations from expected values) in each of the 10 mixtures. If differences in flammability characteristics of a fuel type between full rings and half-full rings might explain potential mixture effects and were significant in a $t$-test, expected values were calculated again by using the value of the half rings of that fuel type. Burns with half-full rings were performed on different days than those with full rings, so that we needed to average values of different days. We therefore randomly picked values of full rings and averaged with values obtained from burns with half rings.

\section{RESULTS \\ FLAMMABILITY DIFFERENCES BETWEEN MONOSPECIFIC FUELS}

There were differences in flammability between the five monospecific fuel types for the three measured flammability variables (Figure 1). For example, Betula branches burned much slower, longer, and generated higher temperatures than Hylocomium. Fuel density was correlated with flame speed $(r=-0.96, N=5$, $P=0.008)$ and duration $(r=0.90, N=5, P=0.036)$, while specific area was the trait most strongly correlated with maximum temperature $(r=-0.94, N=5, P=0.018$; Figure 2$)$. However, density was, according to Spearman's rho, also correlated with temperature $(\rho=0.90, N=5, P=0.037)$ and with specific area $(\rho=-0.90, N=5, P=0.037)$. In contrast, neither $\mathrm{C}: \mathrm{N}$ ratio nor dry matter content or packing ratio was correlated to any flammability characteristic (Spearman rank correlations with $P \geq 0.75$, $P \geq 0.29$, and $P \geq 0.51$ respectively).

\section{FLAMMABILITY DIFFERENCES BETWEEN EXPECTED AND OBSERVED OUTCOME OF MIXTURES}

For 60 total comparisons in 26 showed significant deviation from additive effects (Figure 3) Considering the mass- and volume-weighted analyses together, 21 out of 26 significant nonadditive effects were greater than expected (i.e., dominance effects) flammability. There were four non-additive dominance effects (i.e., greater than expected) for maximum temperature compared to volume-based expectation, but these pairs did not show any deviation from the mass-based expectation (Figure 3). In other words, maximum temperature is very closely predicted by a model of mass-based adaptive mixing; species have effects on the temperature of the burn in proportion to their biomass.

In contrast, for flame speed, five pairs showed faster burning than expected compared to both the mass- and volume-based expectation (Figure 3). In other words, for the rate of fire spread, very flammable species have an effect out of proportion to their biomass, promoting the rapid spread of fire through litter beds.

The volume control rings of Betula branches had a significantly longer flame duration than the full rings (see Appendix), so the usage of only half the amount (and thereby mass and volume) of branches in the mixtures might explain the longer observed compared to expected flaming time in the mixtures with this material. Hylocomium had a significantly shorter flame duration in the volume controls, which could explain the significantly shorter flame duration in the mixture with Betula leaves. Therefore, for these five mixtures expected values were calculated again, resulting in significant non-additivity for the mixtures of Betula branches with Betula leaves and Hylocomium, resulting in a total of 3 out of 10 genuine non-additive mixture effects on flame duration.

For flame speed and maximum temperatures similar results for monospecific half versus full rings indicated that none of the nonadditive effects were confounded by fuel amount (volume or mass) of a component species. In summary, non-additive species mixture effects on flammability variables were frequent for all three different volume or mass-weighted bases on which expected values had been calculated.

\section{DISCUSSION}

We have provided the first explicit experimental demonstration of diversity effects on flammability. As hypothesized, we found non-additive effects in our fuel mixtures for both flame speed and flame duration. Flame speed was higher and flame duration was longer than expected in the mixtures, suggesting that flammable species can influence the temporal dynamics of fire well out of proportion to their biomass. These mixtures all contained the species with the highest flame speeds measured in the monospecific burns, that is, the species with the most extreme values had the most non-additive effects.

In these highly controlled laboratory experimental conditions we have demonstrated the potential for a mechanism that, if confirmed in field fire conditions, could be highly important in systems where a largely non-flammable community is invaded by a flammable species. It is well known that flammable invasive species can highly alter relatively non-flammable ecosystems (d'Antonio and Vitousek, 1992). What we have shown here is one crucial mechanism by which, in the beginning stages of the invasion, the flammable invader could promote the spread of fire out of proportion to its biomass. This non-additive effect could speed the conversion of a low fire frequency system to one in which fires are frequent.

We did not consistently find non-additive effects in mixtures that contained the most flammable species, but rather in mixtures that contained species showing maximum values for a flammability characteristic. These are most probably not caused by interactions between the species in terms of one species enhancing or inhibiting the flammability of the other species directly, as is found in litter mixing studies for decomposition rates (Wardle et al., 1997; Lecerf et al., 2011), but rather by flames spreading via the easiest burning species and the burning time being as long as the longest burning species. The fact that we found dominance effects in several flammability characteristics might be very important for 

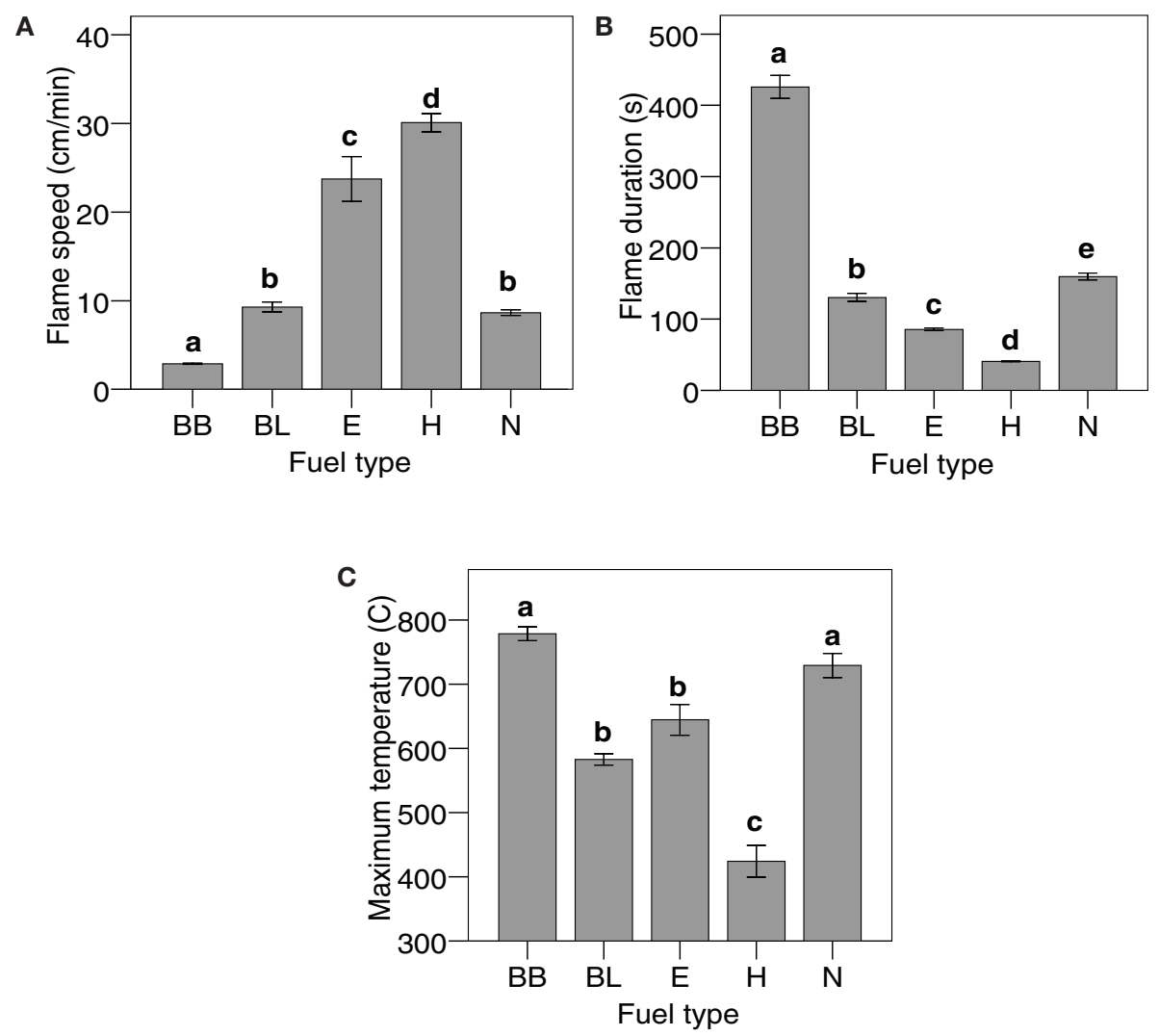

FIGURE 1 | Differences between monospecific fuels (see Table 1 for codes) in (A) flame speed, (B) flame duration (time to extinction) and (C) maximum temperature. Means and SEs indicated, $N=6$ for each material and flammability variable, except for Betula leaves for the variable flame extinction $(N=5)$ and Nephroma for average maximum temperature
$(N=5)$. One-way ANOVA was performed on $\log _{10}$-transformed flame speed $(F=240, P<0.001)$, $\log _{10}$-transformed flame duration $(F=804$, $P<0.001)$ and maximum temperature $(F=56.1, P<0.001)$ with fuel type as a fixed factor. Different letters denote significant differences $(P<0.05$, Tukey post hoc test). vegetation fuel mapping: the temporal dynamics of fire - spread rate and duration - could be determined by the most flammable species in the vegetation. For example, the ground layer vegetation in subarctic heath and woodland is largely dominated by Empetrum and Hylocomium, which our findings suggest should be very flammable.

Surprisingly, we found no dominance effects for maximum temperature in the mixtures that contained Betula branches or Nephroma (except for the Hylocomium-Nephroma mixture), even though these fuel types generated the highest temperatures when monospecific. For temperature, individual species have effects in proportion to their mass in the mixture (Figure 3). This suggests that the maximum temperatures of the fire are much more a function of the chemistry and structure of the entire litter bed and are less sensitive to the traits of extreme species. In an ecological setting, with log-normal abundance distributions, this suggests that the traits of the dominant species will be crucial for the maximum temperature of ground fires.

Overall, we found that non-additive effects were common for the dynamics of fire - spread and duration - in ground fuels, with the most flammable species exerting strong effects on these variables. This implies that rare flammable species can, in some situations, have strong effects on fire dynamics. In contrast, the maximum temperature of the fire is a mass-weighted average of the fuels, suggesting the dominant species are crucial for this flammability variable.

\section{TRAITS AND FLAMMABILITY IN MIXTURES}

Which traits, or trait contrasts, might explain non-additive mixture effects on flammability? Fuel density (of monospecific fuels) was the most important trait to explain the large differences in flammability characteristics in our study (Figure 2). The denser the fuel, the longer it took for a flame to consume it, leading to slow flame spread and a long burning time. Fuel density scales with caloric content per volume (Kataki and Konwer, 2001), so that temperatures can get very high in dense fuels. We therefore propose that fuel density (partly represented here also by specific area, at least for maximum temperature) plays an important role in the enhanced dominance effects. However, it is most likely that the mixture interactions on flammability depend on multiple, interacting traits (cf. Eviner and Chapin, 2003). We did not measure contents of some of the known flammable compounds of plants, such as volatile oils, waxes, and terpenes (Bond and Van Wilgen, 1996). Such secondary metabolites may be particularly important determinants of ignitability (Lavorel and Garnier, 2002; Cornelissen et al., 2003; Plucinski and Anderson, 2008), 

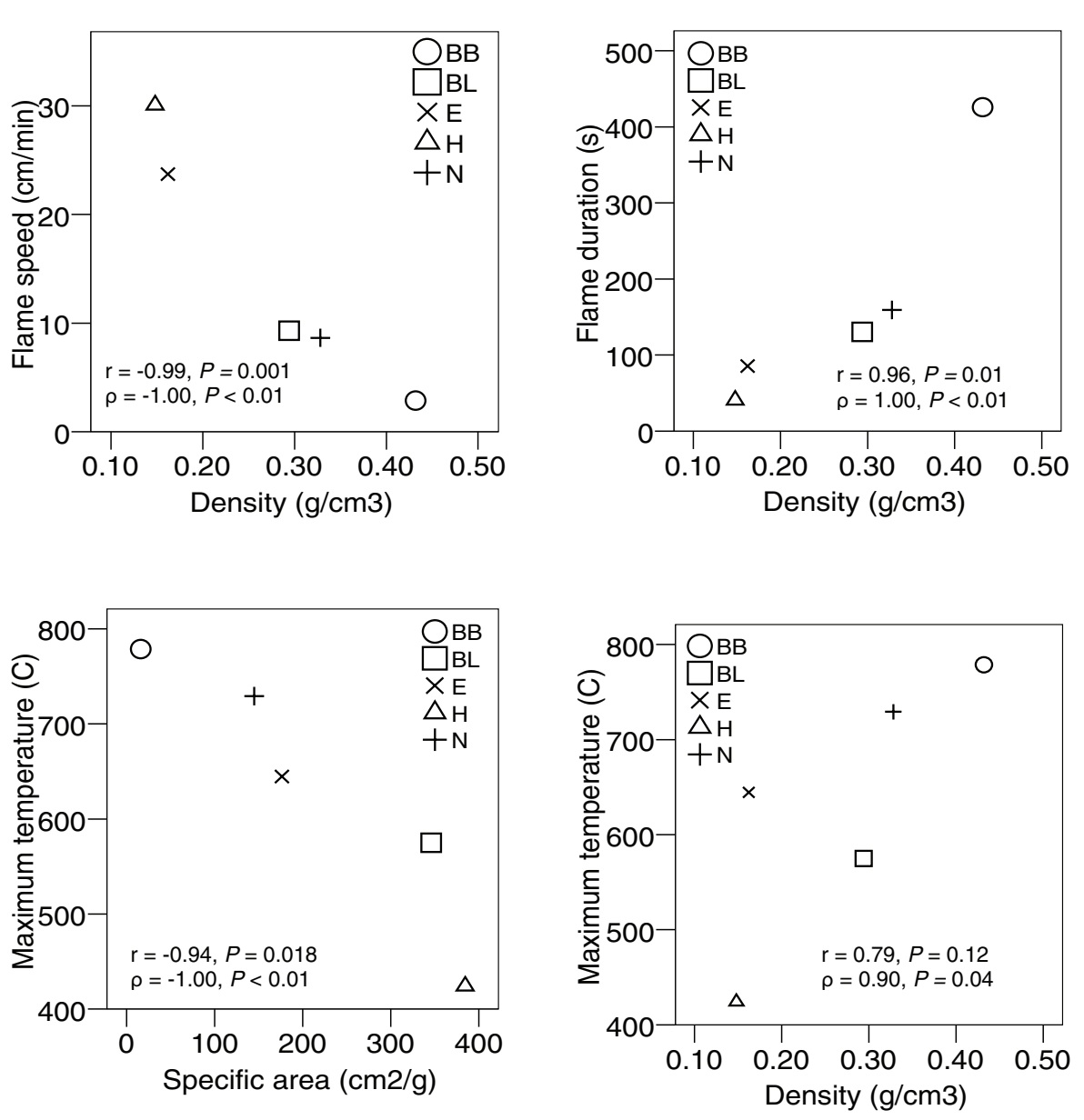

FIGURE 2 | Scatterplots of plant traits versus flammability variables. Symbols denote the five investigated fuel types (see Table 1 for codes). Only the significant relationships are shown.

which may thereby also affect the flame speed and temperature profiles of fires in mixtures. Lignin is also known to affect flammability parameters, for instance by affecting the balance between char and tar formation (reviewed by Cornwell et al., 2009). Packing ratio, on the other hand, has been linked to the combustibility and sustainability of fires (Scarff and Westoby, 2006), and it is therefore surprising that we did not find any correlations with this trait.

If we define a flammable species as one having a very high flame speed and a short burning time, then Empetrum and Hylocomium are the most flammable species of the five investigated fuel types. We can then also conclude that the most flammable species does not necessarily generate the highest temperature: Hylocomium generated the lowest temperatures of all fuel types. Maximum temperature generated might however be an important property of plant species in relation to ignitability when they are standing in mixtures: the heat released from a species that generates high temperatures might ignite, or speed up, the ignition of surrounding species. We chose to focus on the sustainable and combustible aspects of flammability, but it would be interesting to test in mixture studies whether there are interactions between species with a high ignitability and species with a high combustibility. Such mixture effects could be studied at different moisture contents of the plant materials, since moisture content affects ignition thresholds of fuel (Plucinski and Anderson, 2008) and therefore might play an important role in interactions between ignitability and combustibility.

Experimental flammability assays like this one represent a useful mid-point between more controlled calorimeter studies (Madrigal et al., 2009; Belcher et al., 2010) and field experiments and observations (Scarff and Westoby, 2006; Curt et al., 2011; Schwilk and Caprio, 2011). Unlike photosynthesis or decomposition in which the scaling from leaf-level processes to ecosystem carbon fluxes is relatively well-studied, for fire there remains much work to be done. Here we have only begun to explore the trait dimensions through which species affect flammability. More studies need to be conducted to confirm that enhanced dominance effects are prevalent in flammability characteristics, not only for 50:50 fuel mixtures, but also for other mixture ratios, both by volume and by mass, and at different litter depths. By using a range of mixture ratios, a threshold might be detected at which a very 

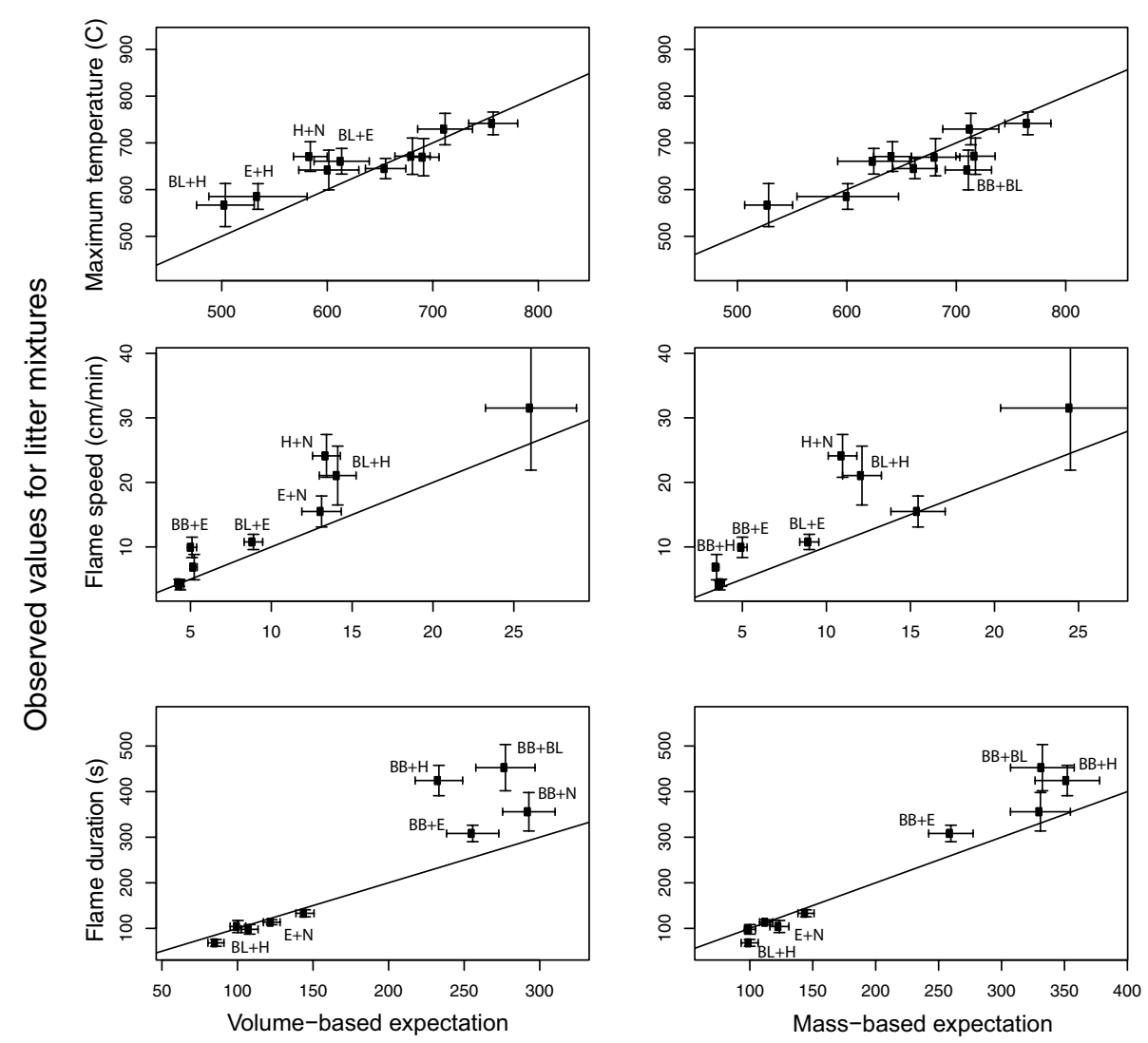

FIGURE 3 | Fire characteristics for all mixtures (see Table 1 for codes). Expected values for 50:50 mixtures by volume are both volume-weighted (left panels) and mass-weighted (right panels). Significant differences between expected and observed values for each mixture of a flammability variable are denoted with the species codes from Table 1. Horizontal and vertical error bars show the $95 \%$ confidence limits $(=1.96 * \mathrm{SE})$ on the estimates of the means. flammable species still dominates over a weakly flammable species. Finally, moisture contents of the plant materials can also be varied to mimic a greater variety of natural conditions. We conducted our experiments with air-dried fuels, a condition that can be found after extensive dry periods, but the flammability of Hylocomium or another moss at increasing water content is also ecologically relevant.

\section{CONCLUSION}

By conducting experiments with mixtures of five contrasting plant materials, we have shown that non-additive effects for several flammability characteristics are indeed possible. These effects were mostly caused by the dominance of the flammability characteristics of one species over the other, leading to greater spread rate compared to additivity. For flame speed, enhanced dominance effects were found for mixtures that contained Empetrum or Hylocomium, the species with the highest flame speed. In summary, in simple experimental conditions, flame speed and time to extinction are determined by the most flammable species in the mixture, i.e., enhanced dominance. In contrast, the maximum temperature

\section{REFERENCES}

ACIA. (2005). Arctic Climate Impact Assessment. Cambridge: Cambridge University Press.
Alessio, G. A., Penuelas, J., De Lillis, M. and Llusia, J. (2008). Implications of foliar terpene content and hydration on leaf flammability of Quercus ilex

of the burn appears to be a mass-weighted mean of the litter mixtures. More research needs to be conducted to translate these very controlled burns to the much less controlled conditions of natural and semi-natural fires, but these experiments provide clear hypotheses about how mixtures of fuels may interact in ecosystems with mixed ground fuels.

\section{ACKNOWLEDGMENTS}

We would like to thank Koert van Geffen and Jeroen Cornelissen for their great help in collecting all plant materials. Willem Reijnders, Lisette Bakker, Christiaan de Leeuw, Bram Elbers, and Jochem Veenboer gave useful suggestions for developing the fire protocol. Ron Lootens produced the TCmeas software. We thank Abisko Research Station and its staff for great hospitality and assistance. This investigation, carried out in the Fire Laboratory Amsterdam for Research in Ecology (FLARE), contributes to the FUTURE project and was financially supported by grant 047.018 .003 of the Netherlands Organisation for Scientific Research (NWO) to JHCC.

and Pinus halepensis. Plant Biol. 10 123-128.

Anderson, H. E. (1970). Forest fuel ignitibility. Fire Technol. 6, 312-319.
Auclair, A. N. D. (1983). "The role of fire in lichen-dominated tundra and forest-tundra," in The Role of Fire in Northern Cicumpolar Ecosystems, eds 
R. W. Wein, and D. A. MacLean (New York: John Wiley \& Sons Ltd), 235-256.

Behm, A. L., Duryea, M. L., Long, A. J., and Zipperer, W. C. (2004). Flammability of native understory species in pine flatwood and hardwood hammock ecosystems and implications for the wildland-urban interface. Int. J. Wildland Fire 13, 355-365.

Belcher, C. M., Mander, L., Rein, G., Jervis, F. X., Haworth, M., Hesselbo, S. P., Glasspool, I. J., and McElwain, J. C. (2010). Increased fire activity at the Triassic/Jurassic boundary in Greenland due to climatedriven floral change. Nat. Geosci. 3, 426-429.

Bond, W. J., and Van Wilgen, B. W. (1996). Fire and Plants. London: Chapman \& Hall.

Bond, W. J., Woodward, F. I., and Midgley, G. F. (2005). The global distribution of ecosystems in a world without fire. New Phytol. 165, 525-537.

Catchpole, E. A., Catchpole, W. R., and Rothermel, R. C. (1993). Fire behavior experiments in mixed fuel complexes. Int. J. Wildland Fire 3, 45-57.

Conard, S. G., and Ivanova, G. A. (1997). Wildfire in Russian boreal forests - potential impacts of fire regime characteristics on emissions and global carbon balance estimates. Environ. Pollut. 98, 305-313.

Cornelissen, J. H. C., Lavorel, S., Garnier, E., Diaz, S., Buchmann, N., Gurvich, D. E., Reich, P. B., ter Steege, H., Morgan, H. D., van der Heijden, M. G. A., Pausas, J. G., and Poorter, H. (2003). A handbook of protocols for standardised and easy measurement of plant functional traits worldwide. Aust. J. Bot. 51, 335-380.

Cornwell, W. K., Cornelissen, J. H. C., Allison, S. D., Bauhus, J., Eggleton, P., Preston, C. M., Scarff, F., Weedon, J. T., Wirth, C., and Zanne, A. E. (2009). Plant traits and wood fates across the globe: rotted, burned, or consumed? Glob. Chang. Biol. 15, 2431-2449.

Curt, T., Schaffhauser, A., Borgniet, L., Dumas, C., Esteve, R., Ganteaume, A., Jappiot, M., Martin, W., N'Diaye, A., and Poilvet, B. (2011). Litter flammability in oak woodlands and shrublands of southeastern France. For. Ecol. Manage. 261, 2214-2222.

d'Antonio, C. M., and Vitousek, P. M. (1992). Biological invasions by exotic grasses, the grass fire cycle, and global change. Annu. Rev. Ecol. Syst. 23, 63-87.
Dimitrakopoulos, A. P. (2001). A statistical classification of Mediterranean species based on their flammability components. Int. J. Wildland Fire 10, 113-118.

Dukes, J. S. (2001). Productivity and complementarity in grassland microcosms of varying diversity. Oikos 94, 468-480.

Eviner, V. T., and Chapin, F. S. (2003). Functional matrix: a conceptual framework for predicting multiple plant effects on ecosystem processes. Ann. Rev. Ecol. Evol. Syst. 34, 455-485.

Flannigan, M. D., Krawchuk, M. A., de Groot, W. J., Wotton, B. M., and Gowman, L. M. (2009). Implications of changing climate for global wildland fire. Int. J. Wildland Fire 18, 483-507.

Ganteaume, A., Jappiot, M., LampinMaillet, C., Curt, T., and Borgniet, L. (2011). Effects of vegetation type and fire regime on flammability of undisturbed litter in Southeastern France. For. Ecol. Manage. 261, 2223-2231.

Garnier, E., Cortez, J., Billes, G., Navas, M. L., Roumet, C., Debussche, M., Laurent, G., Blanchard, A., Aubry, D., Bellmann, A., Neill, C., and Toussaint, J.-P. (2004). Plant functional markers capture ecosystem properties during secondary succession. Ecology 85, 2630-2637.

Gill, A. M., and Moore, P. H. R. (1996). Ignitability of Leaves of Australian Plants. Canberra: CSIRO Division of Plant Industry.

Hättenschwiler, S., Tiunov, A. V., and Scheu, S. (2005). Biodiversity and litter decomposition interrestrial ecosystems. Annu. Rev. Ecol. Evol. Syst. 36, 191-218.

Hector, A. (1998). The effect of diversity on productivity: detecting the role of species complementarity. Oikos 82, 597-599.

Higuera, P. E., Brubaker, L. B., Anderson, P. M., Brown, T. A., Kennedy, A. T., and Hu, F. S. (2008). Frequent fires in ancient shrub tundra: implications of paleorecords for Arctic environmental change. PLoS ONE 3, e0001744. doi:10.1371/journal.pone.0001744

Hooper, D. U., Chapin, F. S., Ewel, J. J., Hector, A., Inchausti, P., Lavorel, S., Lawton, J. H., Lodge, D. M., Loreau, M., Naeem, S., Schmid, B., Setälä, H., Symstad, A. J., Vandermeer, J., and Wardle, D. A. (2005). Effects of biodiversity on ecosystem functioning: a consensus of current knowledge. Ecol. Monogr. 75, 3-35.
Hooper, D. U., and Vitousek, P. M. (1998). Effects of plant composition and diversity on nutrient cycling. Ecol. Monogr. 68 121-149

Jin, Y., and Roy, D. P. (2005). Fireinduced albedo change and its radiative forcing at the surface in northern Australia. Geophys. Res. Lett. 32, L13401.

Jones, B. M., Kolden, C. A., Jandt, R. Abatzoglou, J. T., Urban, F., and Arp C. D. (2009). Fire behavior, weather, and burn severity of the 2007 Anaktuvuk river tundra fire, North Slope, Alaska. Arct. Antarct. Alp. Res. 41, 309-316.

Kataki, R., and Konwer, D. (2001). Fuelwood characteristics of some indigenous woody species of northeast India. Biomass Bioenergy 20, 17-23.

Lavorel, S., and Garnier, E. (2002). Predicting changes in community composition and ecosystem functioning from plant traits: revisiting the Holy Grail. Funct. Ecol. 16, 545-556.

Lecerf, A., Guillaume, M., Kominoski, J., LeRoy, C. J., Bernadet, C., and Swan, M. (2011). Incubation time, functional litter diversity, and habitat characteristics predict litter-mixing effects on decomposition. Ecology 92, 160-169.

Madrigal, J., Hernando, C., Guijarro, M., Diez, C., Marino, E., and de Castro, A. J. (2009). Evaluation of forest fuel flammability and combustion properties with an adapted mass loss calorimeter device. J. Fire Sci. 27, 323-342.

McGill, B. J., Enquist, B. J., Weiher, E. and Westoby, M. (2006). Rebuilding community ecology from functional traits. Trends Ecol. Evol. (Amst.) 21, 178-185.

Michel, P., Lee, W. G., During, H. J., and Cornelissen, J. H. C. (2012). Species traits and their non-additive interactions control the water economy of bryophyte cushions. J. Ecol. 100, 222-231.

O’Donnell, J. A., Turetsky, M. R., Harden, J. W., Manies, K. L., Pruett, L. E., Shetler, G., and Neff, J. C. (2009). Interactive effects of fire, soil climate, and moss on $\mathrm{CO} 2$ fluxes in black spruce ecosystems of interior Alaska. Ecosystems 12, 57-72.

Ormeno, E., Cespedes, B., Sanchez, I. A., Velasco-Garcia, A., Moreno, J. M., Fernandez, C., and Baldy, V. (2009). The relationship between terpenes and flammability of leaf litter. For. Ecol. Manage. 257, 471-482.
Pausas, J. G., and Keeley, J. E. (2009). A burning story: the role of fire in the history of life. Bioscience 59, 593-601.

Pausas, J. G., and Verdu, M. (2008). Fire reduces morphospace occupation in plant communities. Ecology 89, 2181-2186.

Perez-Harguindeguy, N., Blundo, C. M., Gurvich, D. E., Diaz, S., and Cuevas, E. (2008). More than the sum of its parts? Assessing litter heterogeneity effects on the decomposition of litter mixtures through leaf chemistry. Plant Soil 303, 151-159.

Plucinski, M. P. (2003). The Investigation of Factors Governing Ignition and Development of Fires in Heathland Vegetation. Ph.D. thesis, University of New South Wales, ADFA, Canberra.

Plucinski, M. P., and Anderson, W. R. (2008). Laboratory determination of factors influencing successful point ignition in the litter layer of shrubland vegetation. Int. J. Wildland Fire 17, 628-637.

Quested, H. M., Callaghan, T. V., Cornelissen, J. H. C., and Press, M. C. (2005). The impact of hemiparasitic plant litter on decomposition: direct, seasonal and litter mixing effects. $J$. Ecol. 93, 87-98.

Reich, P. B., Peterson, D. W., Wedin, D. A., and Wrage, K. (2001a). Fire and vegetation effects on productivity and nitrogen cycling across a forest-grassland continuum. Ecology 82, 1703-1719.

Reich, P. B., Knops, J., Tilman, D., Craine, J., Ellsworth, D., Tjoelker, M., Lee, T., Wedin, D., Naeem, S., Bahauddin, D., Hendrey, G., Jose, S., Wrage, K., Goth, J., and Bengston, W. (2001b). Plant diversity enhances ecosystem responses to elevated $\mathrm{CO} 2$ and nitrogen deposition. Nature 410, 809-812.

Rocha, A. V., and Shaver, G. R. (2011). Postfire energy exchange in arctic tundra: the importance and climatic implications of burn severity. Glob. Chang. Biol. 17, 2831-2841.

Rothermel, R. C. (1972). A Mathematical Model for Predicting Fire Spread in Wildland Fuels. Ogden, UT: USDA Forest Service Intermountain Forest and Range Experiment Station, 1-40.

Scarff, F. R., and Westoby, M. (2006). Leaf litter flammability in some semi-arid Australian woodlands. Funct. Ecol. 20, 745-752.

Schwilk, D. W., and Ackerly, D. D. (2001). Flammability and serotiny as strategies: correlated evolution in pines. Oikos 94, 326-336. 
Schwilk, D. W., and Caprio, A. C. (2011). Scaling from leaf traits to fire behaviour: community composition predicts fire severity in a temperate forest. J. Ecol. 99, 970-980.

van Wilgen, B. W., Higgins, K. B., and Bellstedt, D. U. (1990). The role of vegetation structure and fuel chemistry in excluding fire from forest patches in the fire-prone fynbos shrublands of South-Africa. J. Ecol. 78, 210-222.

Vernescu, C., and Ryser, R. (2009). Constraints on leaf structural traits in wetlands plants. Am. J. Bot. 96, 1068-1074.

Volokitina, A. V., and Sofronov, M. A. (2002). Vegetation Fuel Classification and Mapping the Short English Variant of the Monograph 'Vegetation and Fuel Classification and Mapping,' Published in Russian. Novosibirsk: SB RAS Publishing House.

Wardle, D. A., Bonner, K. I., and Nicholson, K. S. (1997). Biodiversity and plant litter: experimental evidence which does not support the view that enhanced species richness improves ecosystem function. Oikos 79, 247-258.

Westoby, M., Falster, D. S., Moles, A. T., Vesk, P. A., and Wright, I. J. (2002). Plant ecological strategies: some leading dimensions of variation between species. Annu. Rev. Ecol. Syst. 33, 125-159.
Woodward, F. I., Lomas, M. R., and Kelly, C. K. (2004). Global climate and the distribution of plant biomes. Philos. Trans. R. Soc. Lond. B Biol. Sci. 359, 1465-1476.

Conflict of Interest Statement: The authors declare that the research was conducted in the absence of any commercial or financial relationships that could be construed as a potential conflict of interest.

Received: 06 December 2011; paper pending published: 10 January 2012; accepted: 15 March 2012; published online: 09 April 2012.
Citation: van Altena $C$, van Logtestijn RSP, Cornwell WK and Cornelissen JHC (2012) Species composition and fire: nonadditive mixture effects on ground fuel flammability. Front. Plant Sci. 3:63. doi: 10.3389/fpls.2012.00063

This article was submitted to Frontiers in Functional Plant Ecology, a specialty of Frontiers in Plant Science.

Copyright (c) 2012 van Altena, van Logtestijn, Cornwell and Cornelissen. This is an open-access article distributed under the terms of the Creative Commons Attribution Non Commercial License, which permits non-commercial use, distribution, and reproduction in other forums, provided the original authors and source are credited. 


\section{APPENDIX}
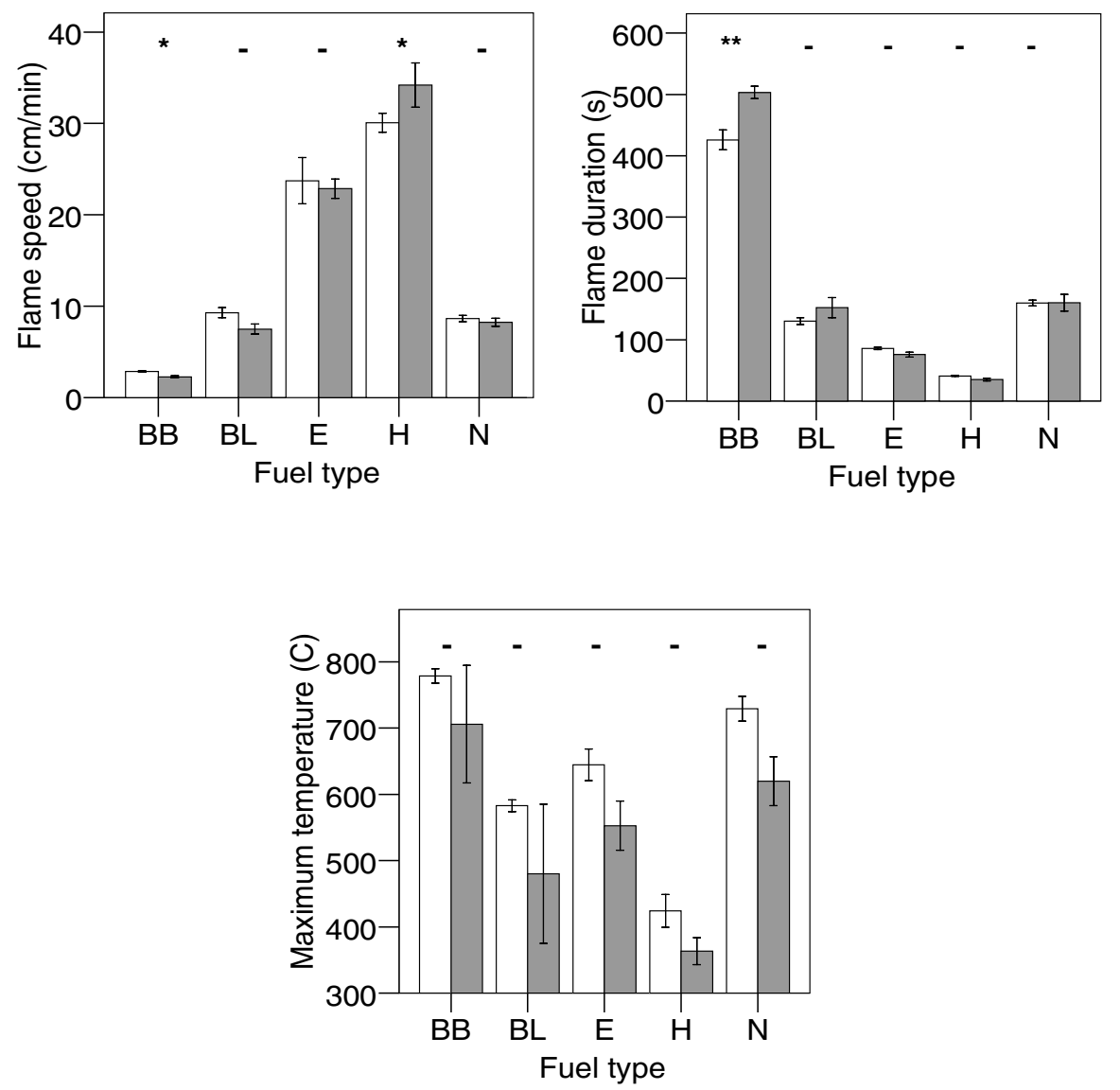

FIGURE A1 | Differences in flammability characteristics for all monospecific fuel types (see Table 1 for codes) between full (white bars) and half full baskets (grey bars). Means and SE are indicated,

$N=6$ for each material and flammability variable, except for Betula leaves for the variable flame duration $(N=5)$ and Nephroma for average maximum temperature $(N=5)$. For half full baskets, $N=3$ for Betula branches and leaves, $N=6$ for Empetrum and Hylocomium, $N=4$ for Nephroma. Significant differences between full and half full baskets for one fuel type are denoted with asterisks ( $t$-test: $-=$ not significant, $\left.{ }^{*} P<0.05,{ }^{*} P<0.01\right)$. 